\title{
Article \\ Elevated Interleukin-6 Levels in the Circulation and Peritoneal Fluid of Patients with Ovarian Cancer as a Potential Diagnostic Biomarker: A Systematic Review and Meta-Analysis
}

\author{
Hina Amer (D), Apriliana E. R. Kartikasari *,+ and Magdalena Plebanski † \\ School of Health and Biomedical Science, Royal Melbourne Institute of Technology, Melbourne, VIC 3000, \\ Australia; S3792283@student.rmit.edu.au (H.A.); magdalena.plebanski@rmit.edu.au (M.P.) \\ * Correspondence: april.kartikasari@rmit.edu.au \\ † Equally contributed.
}

Citation: Amer, H.; Kartikasari, A.E.R.; Plebanski, M. Elevated Interleukin-6 Levels in the Circulation and Peritoneal Fluid of Patients with Ovarian Cancer as a Potential Diagnostic Biomarker: A Systematic Review and Meta-Analysis. J. Pers. Med. 2021, 11, 1335. https://doi.org/ 10.3390/jpm11121335

Academic Editors: Giorgia Garganese, Benedetta Gui and Simona

Maria Fragomeni

Received: 17 October 2021

Accepted: 3 December 2021

Published: 9 December 2021

Publisher's Note: MDPI stays neutral with regard to jurisdictional claims in published maps and institutional affiliations.

Copyright: (c) 2021 by the authors. Licensee MDPI, Basel, Switzerland. This article is an open access article distributed under the terms and conditions of the Creative Commons Attribution (CC BY) license (https:/ / creativecommons.org/licenses/by/ $4.0 /)$.

\begin{abstract}
Ovarian cancer (OC) is one of the most lethal cancers, largely due to a late diagnosis. This study aimed to provide a comprehensive meta-analysis on the diagnostic performance of IL6 in the blood and ascites separately for advanced and early-stage OC. We included 37 studies with 6948 participants detecting serum or plasma IL6. The plasma/serum IL6 mean level in the late-stage OC was $23.88 \mathrm{pg} / \mathrm{mL}$ (95\% CI: 13.84-41.23), and the early-stage OC was $16.67 \mathrm{pg} / \mathrm{mL}$ (95\% CI: 510.06-27.61), significantly higher than the healthy controls at $3.96 \mathrm{pg} / \mathrm{mL}$ (95\% CI: 2.02-7.73), but not significantly higher than those found in the controls with benign growths in the ovary, which was $9.63 \mathrm{pg} / \mathrm{mL}$ (95\% CI: 4.16-22.26). To evaluate IL6 in ascites as a diagnostic marker, we included 26 studies with 1590 participants. The mean level of ascitic IL6 in the late-stage OC was $3676.93 \mathrm{pg} / \mathrm{mL}$ (95\% CI: 1891.7-7146.7), and the early-stage OC was $1519.21 \mathrm{pg} / \mathrm{mL}$ (95\% CI: 604.6-3817.7), significantly higher than the benign controls at 247.33 pg/mL (95\% CI: 96.2-636.0). There was no significant correlation between the levels of circulating and ascitic IL6. When pooling all OC stages for analysis, we found that serum/plasma IL6 provided 76.7\% sensitivity (95\% CI: $0.71-0.92$ ) and $72 \%$ specificity (95\% CI: $0.64-0.79$ ). Ascitic IL6 provided higher sensitivity at $84 \%$ (95\% CI: 0.710-0.919) and specificity at 74\% (95\% CI: 0.646-0.826). This study highlights the utility of ascitic IL6 for early detection of OC.
\end{abstract}

Keywords: ovarian cancer; interleukin-6; diagnosis; prognosis; serum; plasma; ascites; tumor microenvironment

\section{Introduction}

Ovarian cancer (OC) is a gynecological malignancies initiated from the ovaries of the female reproductive system [1]. It is one of the most lethal cancers and poses a significant burden to morbidity and mortality in the affected female population [2]. Despite the extensive cytoreductive surgeries and agonizing chemotherapies, survival rates of women with ovarian cancers are still less than $50 \%$. This is because currently there is no effective screening method available to detect OC at its early controllable stage.

Like most cancers, $\mathrm{OC}$ is a heterogenous, multistage disease where an initial localized abnormal tissue growth can spread later to distinct tissues [3]. The triggering agents can be carcinogens present in physical, chemical, or biological forms [4]. A person's genetic makeup and familial history of OC and breast cancers increase the risk of developing OC [5]. Additionally, unhealthy eating habits, sedentary lifestyles, and aging may also contribute as risk factors [5-9].

The Federation of Gynecology and Obstetrics (FIGO) classified OC to four distinct stages: stage I, stage II, stage III, and stage IV [10]. The staging is a multilevel evaluation of the disease that aids the management plans and predicts the fate of the women with the disease. The early stages, stages I and II, are confined to the ovaries and within the pelvis, 
respectively. Stages III and IV are late stages involving the spread of cancer cells to various nearby and distinct organs traveling via various physiological channels. The Surveillance, Epidemiology and End Result program (SEER) statistical data in 2018 show that the 5-year survival of women with OC is more than $90 \%$ if diagnosed at an early stage compared to less than $20 \%$ at a late stage [11,12]. However, the disease is diagnosed at an inevitable late malignant stage in more than $75 \%$ of OC cases, mainly due to two reasons. Firstly, patients usually are asymptomatic or present with vague non-specific symptoms at early stages [12] Secondly, the unavailability of minimally invasive screening procedures, leading patients to undergo invasive surgical biopsies to be correctly diagnosed and stagged [13].

Cancer-specific biomarkers circulating in the blood can be utilized in minimally invasive diagnostic procedures to detect the presence of cancers [13]. In OC, although not specific, Carcinogen Antigen 125 (CA125) and Human Epididymis 4 (HE4) are approved circulating biomarkers used at clinics for OC monitoring and follow-ups [14]. At late stages, CA125 levels directly correlate to tumor burden, and thus it is a reasonable biomarker to follow up patients with post cytoreductive surgery. However, at early stages, CA125 levels may not be increased substantially, possibly due to the low number of tumor cells present, and moreover, its levels can be induced by other physiological conditions including pregnancy, menstruation, and menopause, as well as certain benign conditions such as endometriosis [15]. HE4 is expressed by epithelial cells of the ovaries [16]. HE4 expression is amplified by the increased cancerous growth of ovarian cells, with the excess of HE4 being produced spilling into the circulation. Several studies have proposed HE4 as a superior diagnostic biomarker to CA125, particularly in pre-menopausal women [17]. However, HE4 cannot detect OC at its early stage [18]. Similar to CA125, HE4 expression levels are influenced by pregnancy and aging [19]. According to these observations, the two biomarkers may not be sufficiently accurate for early-stage OC diagnosis [20].

Recent studies have highlighted the potential role of cytokines in tumor formation, progression, and metastasis to distant organs [21,22]. The pleiotropic interleukin-6 (IL6) is a cytokine that has been implicated in many cancers [23]. In breast cancer, for example, IL6 is not only involved in its pathogenesis, but it has also been proposed as a diagnostic biomarker and a potential therapeutic target [24]. In OC, IL6 appeared to provide high accuracy to detect stages III and IV [25,26]. Several studies have used IL6 in combination with other circulating biomarkers to provide improved sensitivity (correctly diagnosing a patient with a disease) and specificity (correctly diagnosing a patient without a disease) for OC detection [27]. Additionally, not less than $75 \%$ of women with OC developed ascitic fluid in their abdomen. This fluid plays an active role in tumor development and contains diverse acellular fractions including cytokines [28]. IL6 is among the most abundant in ascites, and its concentrations in ascites are a thousand-fold higher than that in the serum [28]. Ascitic IL6 thus has the potential to be used as a minimally-invasive diagnostic biomarker for OC. Biomarkers with high sensitivity and specificity that facilitate early detection will improve quality of life by increasing progression-free and overall survival of OC patients [27,29].

Here, we aimed to determine the utility of serum/plasma and ascitic IL6 for the detection of OC separately at early and late disease stages. To that end, we perform a comprehensive meta-analysis on the diagnostic performance of IL6 with an interest to see whether IL6 has the potential to detect not only the late-stage, but also the early-stage OC.

\section{Materials and Methods}

\subsection{Study Design}

This study aimed to strategically evaluate information from published studies with meta-analysis, synthesize the pattern of IL6 levels during OC development, and evaluate the evidence of the diagnostic utility of IL6 for OC. The research was carried out by the authors through authentic scientific databases and in agreement with statements provided by "Preferred Reporting Items for Systemic Reviews and Meta-Analysis" (PRISMA) [30]. 


\subsection{Search Strategy}

The literature was searched systematically in PubMed and Embase databases up to November 2021 for studies investigating the associations between biomarkers IL6 and ovarian cancer. The text word search included ("IL-6", "IL6", or "Interleukin-6"), ("ovary", or "ovarian"), and ("cancer, cancers, carcinoma", "tumor", "neoplasm", "malignant", or "malignancy"). The selection of articles for studies was based on defined inclusion and exclusion criteria. Titles and abstracts were first manually screened by two authors (H.A. and A.K.). The eligible studies included were peer-reviewed when the full text is available. No restriction to time or age was applied. Additional search by scanning the reference lists from related articles was also performed.

In vitro studies and studies using animal models were set as exclusion criteria. Case studies, previous meta-analyses, reviews, conference papers, and unpublished articles were excluded. Duplicates were removed using endnote software, and articles with full available text and relevant results were included for meta-analysis. Relevant articles were then manually reviewed by two authors (H.A. and A.K.) and selected on the basis of the content of the articles. The inclusion criteria included (1) the study being on ovarian cancer, and (2) the biomarker of interest being soluble IL6 in serum/plasma or peritoneal fluid.

\subsection{Quality Assessment}

An article's quality was assessed by noting the author, year, abstract, and number of citations. Moreover, blood handling, ascitic fluid extraction methods, storage, transportation, and use of appropriate statistics for data analysis in method sections of the articles (where available) were observed to assess experimental quality maintained by the researchers. For study fitness, the updated STrengthening the Reporting of OBservational studies in Epidemiology (STROBE) checklist was used to check the quality assessment of the included articles [31].

\subsection{Data Collection and Extraction}

Two reviewers (H.A. and A.K.) recorded data from all studies that met inclusion criteria using a standardized data collection procedure. The author's name, country, year, and type of study were taken (Supplementary Table S1). Total patients and further division of healthy and benign controls were recorded. Patients truly suffering from ovarian cancer were recorded as malignant. To evaluate early and late stages, we organized all the patients under 4 types of FIGO stages. Stage I and II were considered early stages, and III and IV as late stages, as most studies provided the combined values. The IL6 levels in serum/plasma and ascitic fluid were recorded. Similarly, other parameters such as sensitivity and specificity from the receiver operating characteristics (ROC) analysis were recorded.

\subsection{Data Analysis and Statistics}

The changes in IL6 levels in various OC stages were mapped by determining the pooled mean values of IL6 concentrations in serum/plasma and ascites from the controls and diverse OC stages. The data were effectively separated into 4 groups: healthy, benign, early-stage OC, and late-stage OC. To acquire the pooled mean value, we obtained the mean and standard deviation (SD) of IL6 concentrations from selected studies. When median values were recorded, we estimated the mean values following Cochrane recommendations, with established optimal formulation [32]. We then weighted the mean from each study on the basis of the sample size. As IL6 is expected to display log beta distribution, we constructed the $95 \%$ CI following log-transformed data. We applied the Tukey test for multiple comparison analysis. We then back-transformed the variables that had been log-transformed for reporting purposes. Additionally, we performed a linear regression analysis in log space to evaluate the correlation between serum/plasma and ascitic IL6 concentrations. 
To further evaluate the diagnostic utility of IL6, we extracted the sensitivity and specificity values from the selected studies. We back-calculated the true positive (FP), true negative (TN), false positive (FP), and false negative (FN) on the basis of the sample sizes [33]. The formulas used for the calculations are as follows: sensitivity: TP/(TP + FN), specificity: TN/(FP $+\mathrm{TN})$. The overall sensitivity and specificity values were obtained using a random effect model at $95 \% \mathrm{CI}$. The between-study heterogeneity was calculated using the $\mathrm{I}^{2}$ test. We generated forest plots using OpenMeta (Analyst) ${ }^{\circledR} \mathrm{V} .12 .11 .14$ (Brown University, Providence, RI, USA) [34].

\section{Results}

\subsection{Study Selection and Characterization}

The PRISMA flow chart (Figure 1) shows the number of studies searched from PubMed and Embase. A total of 2189 articles were identified. The duplicates of 1084 articles were removed from the selection, and 1105 records were thus selected for screening. After reading the title and the abstract, we removed 286 animal studies, 222 secondary articles, 453 in vitro studies, and 73 conference articles. After removing these articles, 71 studies were included for complete analysis. Then, following our inclusion criteria, the final 55 articles involving IL6 assessed in serum and ascitic fluid of ovarian cancer patients were added for the meta-analysis. With further detailed evaluation, we were able to retrieve 28 studies for IL6 levels only in serum, 15 only in ascites fluid, and 12 both in serum and ascites fluid. All studies are listed in Table 1.

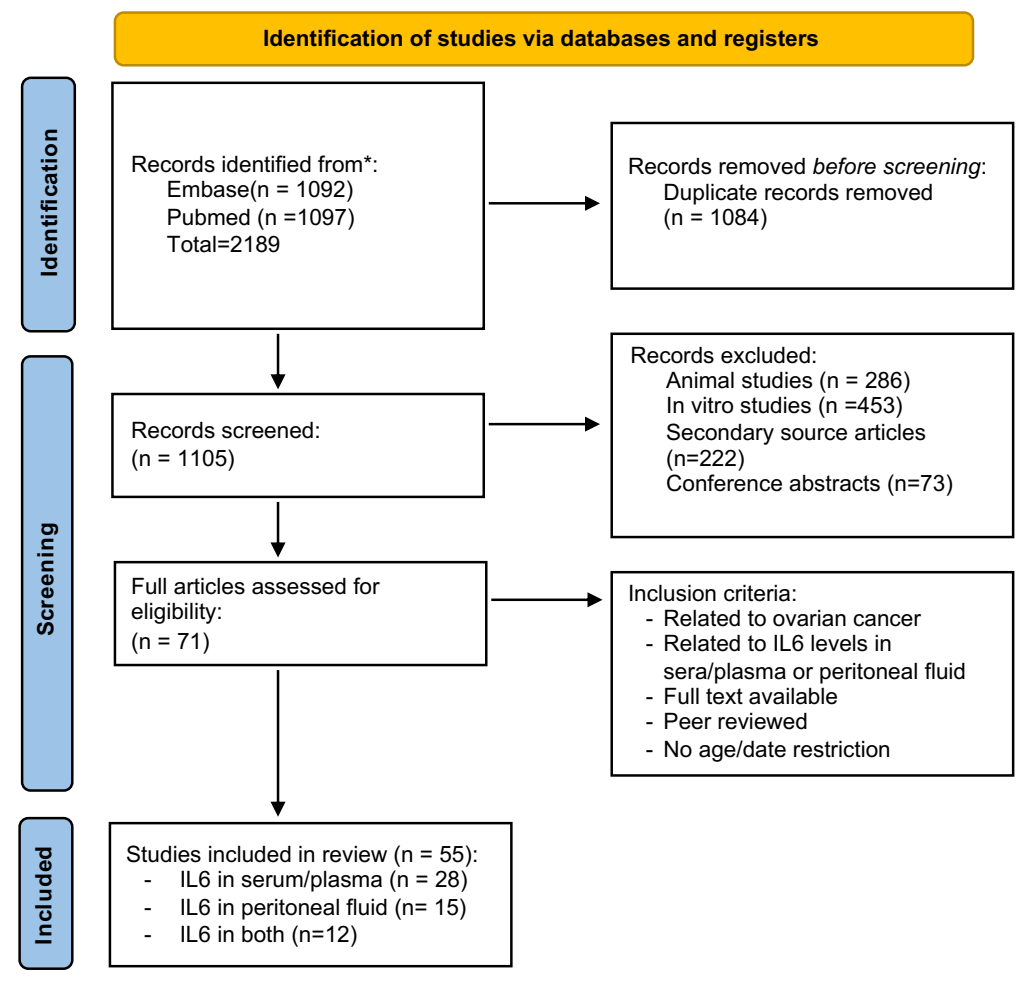

Figure 1. The PRISMA flowchart of the article selection. The steps of our study selection are depicted as a flowchart following PRISMA recommendations.

Table 1. The pooled weighted means of IL6 levels in serum/plasma with 95\% CI.

\begin{tabular}{cccccc}
\hline Type & $\begin{array}{c}\text { Number of } \\
\text { Studies }\end{array}$ & $\begin{array}{c}\text { Pooled Weighted } \\
\text { Mean }(\mathbf{p g} / \mathbf{m L})\end{array}$ & $\begin{array}{c}\text { 95\% Confident } \\
\text { Interval }\end{array}$ & $\begin{array}{c}p \text {-Value (Post-Hoc: OC } \\
\text { vs. Healthy Controls }\end{array}$ & $\begin{array}{c}p \text {-Value (Post-Hoc OC } \\
\text { vs. Benign Controls }\end{array}$ \\
\hline Healthy controls & 20 & 3.96 & $2.02-7.73$ & & \\
Benign controls & 21 & 9.62 & $4.16-22.26$ & & \\
Early-stage OC & 20 & 16.67 & $10.06-27.61$ & 0.018 & 0.650 \\
Late-stage OC & 20 & 23.88 & $13.84-41.23$ & 0.002 & 0.225 \\
\hline
\end{tabular}




\subsection{STROBE Checklist}

All the articles were assessed for their fitness following the STROBE checklist criteria. It includes author, country, year of publication, introduction describing the background of the study, study design, care taken while handling samples, and valid results through using valid statistical tools. All selected articles passed the STROBE checklist criteria (Supplementary Table S2). These include the articles of Sanna et al. [35], Micheli et al. [36], de Lima et al. [37], Rodrigues et al. [38], Kampan et al. [25], Wertel et al. [39], Zhang et al. [40], Crispim et al. [41], Shi et al. [42], Li et al. [43], Dalal et al. [44], Han et al. [45], Kumar et al. [46], Martins-Filho et al. [47], Cantón-Romeo et al. [48], Sanguinette et al. [49], Hao et al. [50], Mikuła-Pietrasik et al. [51], Chudecka-Głaz et al. [52], Block et al. [53], Matsuo et al. [54], Ose et al. [55], Lane et al. [56], Trabert et al. [57], Cândido et al. [58], Poole et al. [59], Dobrzycka et al. [60], Matte et al. [61], Autelitano et al. [27], Clendenen et al. [62], Sen et al. [63], Yigit et al. [64], Edgell et al. [65], Nowak et al. [66], Napoletano et al. [67], Tsai-Turton et al. [68], Amonkar et al. [69], Macciò et al. [70], Lutgendorf et al. [71], Kavask et al. [72], Lambeck et al. [73], Chechlinska et al. [74], Costanzo et al. [75], Macciò et al. [76], Gorelik et al. [77], Daraïet al. [78], Dobryszyca et al. [79], Tempfer et al. [80], Scambia et al. [81], Plante et al. [82], Schröder et al. [83], van der Zee et al. [84], Moradi et al. [85], Gastl et al. [86], and Berek et al. [87] (Supplementary Tables S1 and S2).

\subsection{IL6 Levels in the Circulation and Ascites}

To evaluate the involvement of IL6 in OC staging and its potential to be used as a diagnostic biomarker, we selected published papers that provide us with the data on IL6 concentrations in serum/plasma and/or ascites from stage-specific OC patients and healthy or benign controls. All selected articles used immuno-based assays including enzyme-linked immunosorbent assay (ELISA) as a method of detection. For plasma/serum IL6 concentrations, we extracted data from a total of 37 studies with 6948 participants. The weighted pooled mean values of IL6 in patients with late-stage OC at $23.88 \mathrm{pg} / \mathrm{mL}$ (95\% CI: 13.84-41.23) were significantly higher ( $p$-value $<0.001)$ than that of the healthy controls at $3.96 \mathrm{pg} / \mathrm{mL}$ (95\% CI: 2.02-7.73). Interestingly, the weighted mean values of IL6 in patients with early-stage OC at $16.67 \mathrm{pg} / \mathrm{mL}$ (95\% CI: 510.06-27.61) were also significantly higher than that of the healthy controls ( $p$-value $<0.05)$. However, when compared to the weighted pooled mean values of the benign controls at $9.63 \mathrm{pg} / \mathrm{mL}$ (95\% CI: 4.16-22.26), although the trend was similar to the comparison with the healthy controls, the differences were not significant for both the late-stage as well as the early-stage OC ( $p$-values of the difference are 0.225 and 0.650 , respectively) (Figure 2, Table 1). This result shows the potential of serum/plasma IL6 concentrations as diagnostic biomarkers to detect OC at both early and late stages when compared to the healthy controls. However, the serum/plasma IL6 levels may not be accurate to distinguish between benign and OC growth.

We also gathered 26 studies with 1590 participants in order to evaluate the changes in IL6 levels in the peritoneal fluids from women with OC compared to the benign controls. The weighted pooled mean value of IL6 levels in the ascites from the late-stage OC was $3676.93 \mathrm{pg} / \mathrm{mL}$ (95\% CI: 1891.7-7146.7), while from the early-stage was $1519.21 \mathrm{pg} / \mathrm{mL}$ (95\% CI: 604.6-3817.7). Both mean values were significantly higher than the benign controls at $247.33 \mathrm{pg} / \mathrm{mL}$ (95\% CI: 96.2-636.0) ( $p$-value $<0.001$ and $<0.05$, respectively) (Figure 3, Table 2). This result indicates that ascitic IL6 is a useful diagnostic biomarker to detect both the late-stage as well as the early-stage OC.

Table 2. The pooled weighted means of IL6 levels in ascites with 95\% CI.

\begin{tabular}{|c|c|c|c|c|}
\hline Type & Number of Studies & $\begin{array}{l}\text { Pooled Weighted } \\
\text { Mean }(\mathrm{pg} / \mathrm{mL})\end{array}$ & $\begin{array}{l}\text { 95\% Confident } \\
\text { Interval }\end{array}$ & $\begin{array}{c}p \text {-Value (Post-Hoc OC } \\
\text { vs. Benign) }\end{array}$ \\
\hline Benign & 16 & 247.33 & $96.2-636.0$ & \\
\hline Early-stage OC & 11 & 1519.21 & $604.6-3817.7$ & 0.0195 \\
\hline Late-stage OC & 13 & 3676.92 & $1891.7-7146.7$ & 0.0002 \\
\hline
\end{tabular}




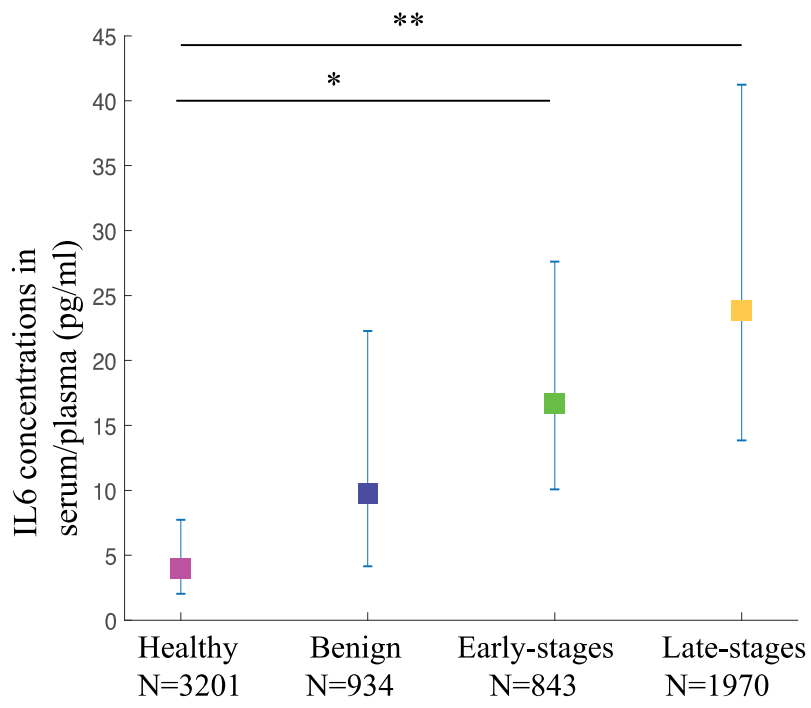

Figure 2. The circulating IL6 levels are higher in various OC stages compared to the healthy controls. IL6 levels in serum/plasma from OC and controls are depicted as pooled weighted means \pm $95 \%$ CI. Multiple comparison analysis was performed by Tukey test. ${ }^{*} p$-value $<0.05,{ }^{* *} p$-value $<0.01$.

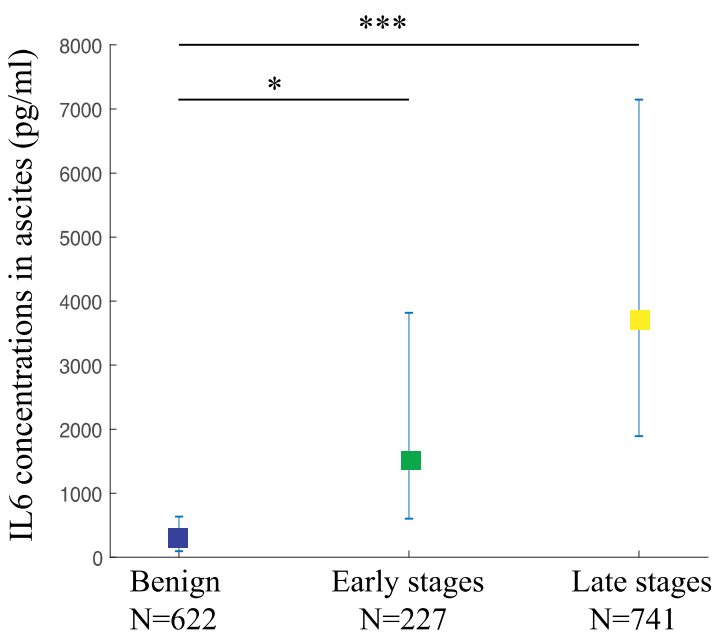

Figure 3. The ascitic IL6 levels are higher in various OC stages compared to the benign controls. IL6 levels in ascites from OC and controls are depicted as pooled weighted means $\pm 95 \%$ CI. Multiple comparison analysis was performed by Tukey test. ${ }^{*} p$-value $<0.05,{ }^{* * *} p$-value $<0.001$.

We further evaluated the correlation between serum/plasma and ascitic IL6 levels in order to determine the potential of using serum/plasma IL6 concentrations as a surrogate marker predicting the levels of IL6 in ascites. We extracted the data from studies that measure IL6 concentrations in both serum/plasma and ascites from the exact same participants. We performed linear regression analysis to evaluate the correlation (Figure 4). We noticed the trend increase in the combined mean values of serum/plasma as well as ascitic IL6 on the basis of OC staging (Figure 4). However, due to the large spread of IL6 values, there was no correlation observed between serum/plasma IL6 levels and ascitic IL6 levels ( $p$-value $=0.84, \mathrm{R}^{2}=0.00193$ ), suggesting that the levels of IL6 in the circulation cannot be used as a surrogate marker to predict IL6 levels in peritoneal fluid. Figure 4 also shows that the increased levels of proinflammatory IL6 in peritoneal fluid from the OC groups are 100 times higher than that in the circulation, indicating the involvement of inflammation in OC development. 


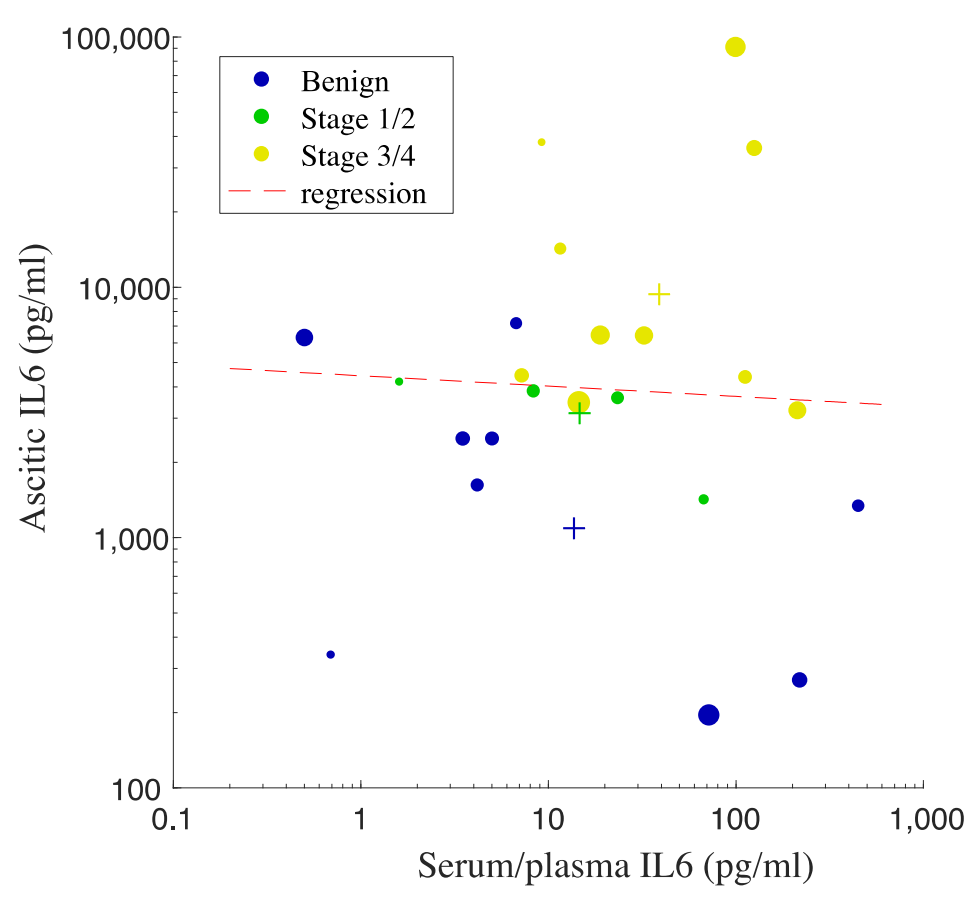

Figure 4. Linear regression analysis for the correlation between IL6 in serum/plasma vs. ascites. Each dot represents the mean value, and the size of the dot correlates with the number of participants from each study. Each plus sign indicates the pooled mean value of IL6 from each OC or benign group. IL6 concentrations are in $\mathrm{pg} / \mathrm{mL}$ The color of the plus signs matches that of the data points.

\subsection{Sensitivities and Specificities}

Here, we extracted data from 12 selected articles that provide sensitivity and specificity values for IL6 as a diagnostic biomarker for across various OC stages (Supplementary Table S3). In serum/plasma, in comparison to the benign controls, the overall values of sensitivity and specificity for IL6 to detect OC of various stages were 76.7\% (95\% CI: $0.71-0.92)$ and $72 \%$ (95\% CI: 0.64-0.79), respectively. In ascites, the overall sensitivity and specificity were $84 \%$ (95\% CI: $0.710-0.919)$ and $74 \%$ (95\% CI: $0.646-0.826)$, respectively (Table 3, Figure 5). The heterogeneity levels of sensitivity and specificity values described as $\tau^{2}$ (Table 3) showed low heterogeneity between data in all chosen studies. These results thus indicate favorable accuracy for both serum/plasma and ascitic IL6 to predict OC at various stages. This meta-analysis result, however, did not provide direct evidence for the utility of IL6 as an early OC detector, as the data came from the combination measures of both early and late OC stages.

Table 3. The overall sensitivity and specificity performance of serum/plasma or ascitic IL6 to correctly indicate the presence of OC from healthy and benign controls.

\begin{tabular}{|c|c|c|c|c|c|c|c|c|c|}
\hline \multirow{2}{*}{ Type } & \multirow{2}{*}{$\begin{array}{l}\text { Number of } \\
\text { Studies }\end{array}$} & \multicolumn{4}{|c|}{ Sensitivity } & \multicolumn{4}{|c|}{ Specificity } \\
\hline & & Overall & $95 \%$ CI & $p$-Value & $\tau^{2}$ & Overall & $95 \% \mathrm{CI}$ & $p$-Value & $\tau^{2}$ \\
\hline $\begin{array}{l}\text { Serum/plasma IL6 } \\
\text { for mixed stages }\end{array}$ & 7 & $76.7 \%$ & $0.646-0.856$ & $<0.001$ & 0.433 & $72 \%$ & $0.638-0.790$ & $<0.001$ & 0.165 \\
\hline $\begin{array}{l}\text { Ascitic IL6 for } \\
\text { mixedstages }\end{array}$ & 5 & $84 \%$ & $0.710-0.919$ & $<0.001$ & 0.492 & $74 \%$ & $0.646-0.826$ & $<0.001$ & 0.112 \\
\hline \multirow{2}{*}{$\begin{array}{l}\text { IL6 as one of the } \\
\text { combined marker } \\
\text { for early stage OC }\end{array}$} & $\begin{array}{l}\text { Gorelik } \\
\text { et al., } 2005\end{array}$ & $84.1 \%$ & \multicolumn{3}{|c|}{$\begin{array}{c}\text { Combined with CA124, GCSF, EGF } \\
\text { and VEGF }\end{array}$} & $75.7 \%$ & \multicolumn{3}{|c|}{$\begin{array}{l}\text { Combined with CA124, GCSF, EGF } \\
\text { and VEGF }\end{array}$} \\
\hline & $\begin{array}{l}\text { Han et al., } \\
2018\end{array}$ & $84.2 \%$ & \multicolumn{3}{|c|}{ Combined with CA125, HE4 and ECAD } & $95.7 \%$ & \multicolumn{3}{|c|}{$\begin{array}{l}\text { Combined with CA125, HE4 } \\
\text { and ECAD }\end{array}$} \\
\hline
\end{tabular}




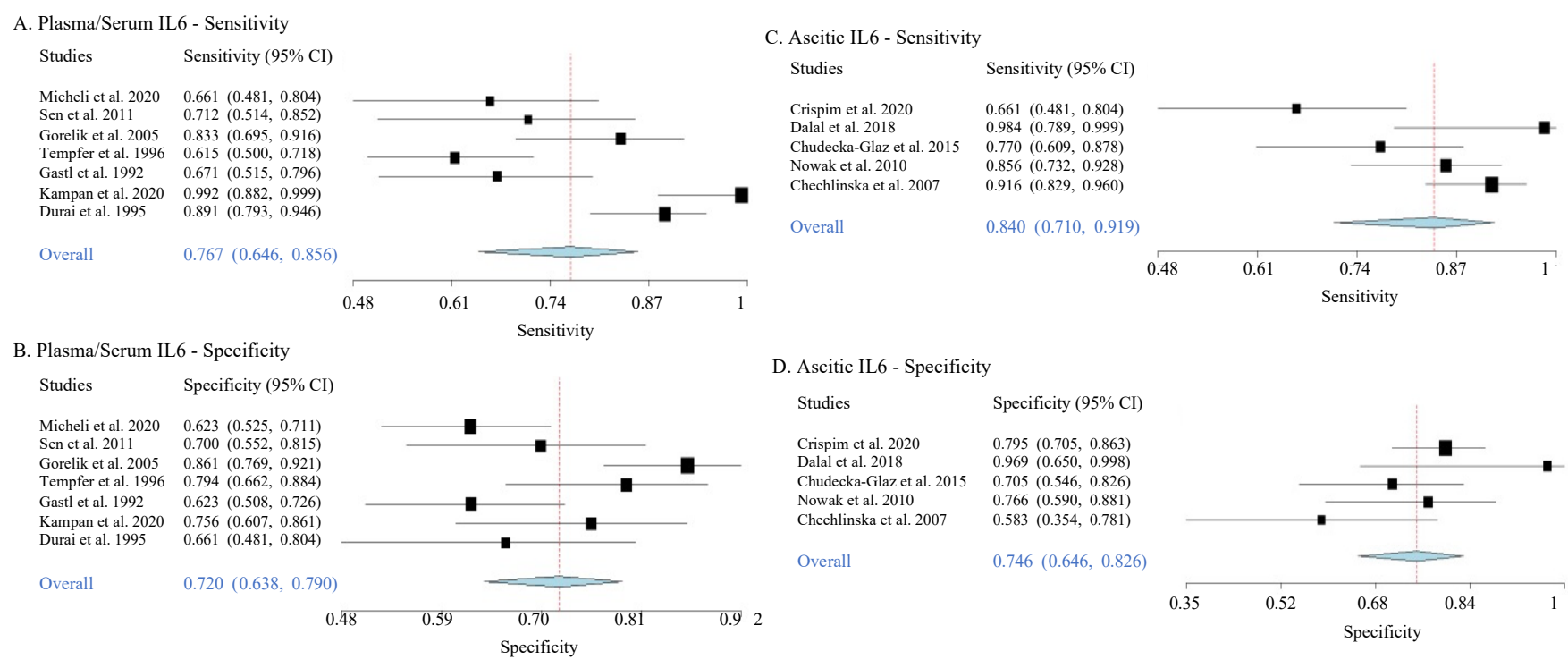

Figure 5. Forest plots of sensitivity and specificity of plasma/serum and ascitic IL6 to diagnose OC. The forest plots are generated from the sensitivity and specificity data from various studies when predicting the presence of ovarian cancer (mixed stages) from the benign controls. Each blue diamond indicates the summary of overall sensitivity or specificity from each plot.

Interestingly, Gorelik et al. (2005) shows that IL6 as a single serum biomarker provided $84.1 \%$ sensitivity and $86 \%$ specificity in predicting OC exclusively at the early stages in comparison to benign controls. Furthermore, in combination with other markers, two studies showed that IL6 provides accurate prediction for the presence of OC at early stages. The first study was by Gorelik et al. (2005), showing that IL6 combined with CA125, GCSF, EGF, and VEGF provided $84.1 \%$ sensitivity and $75.7 \%$ specificity. The second study was by Han et al. in 2008, showing that when IL6 was combined with CA125, HE4, and ECAD, $84.2 \%$ sensitivity and $95.7 \%$ specificity were achieved (Table 3 ). These studies thus suggest that circulating IL6 has an additional value to predict OC at the early stages when combined with other markers.

\section{Discussion}

OC remains to be the most lethal cancer of the reproductive system, with an overall 5 year survival rate of only $46 \%$, due to late diagnosis in more than $75 \%$ of the patients. In advanced or late stages, women may respond to initial treatment. However, as the recurrence rate is very high, the late-stage disease leads to a very low survival rate. Thus, early diagnosis of this disease is the key to improving survival from OC.

As there is currently no effective screening procedure for $\mathrm{OC}$, in addition to its vague symptoms, more research needs to be done to tackle the difficulties in diagnosing this disease. Thus, knowledge in the etiology and mechanism of OC may shed light on both better diagnosis and treatment for this disease. It has been frequently proposed that inflammation, orchestrated by cytokines, may be the driver that induces OC [22]. Within the tumor microenvironment, the OC cells and other stromal cells secrete proinflammatory cytokines, such as IL6 and others. Several studies have further shown that increased inflammation levels in the tumor microenvironment promote poorer prognosis for OC (reviewed in [22,29]). Here, we analyzed published articles in Medline and Embase databases that measured IL6 in the circulation and the peritoneal fluid of women with OC in order to provide fundamental baselines on the absolute concentration levels of IL6 in various stages of this disease, as well as to determine the potential of IL6 as a biomarker for not only the late-stage, but also for the detection of the early-stage OC, which is currently difficult to diagnose. By calculating the pooled weighted mean values followed by post hoc tests, we found that IL6 levels in the circulation were increased in both early- and late-stage OC 
in comparison to healthy and benign controls. However, the increased plasma/serum IL6 levels were only significant when OC samples were compared to the healthy control samples. This shows that IL6 has the potential to be a diagnostic biomarker to detect OC formation, but it may not be specific enough to distinguish it from benign growth. In contrast, we show a significant increase of IL6 concentrations in the ascites of OC patients, both at the early and late stages, in comparison to benign controls. Thus, this highlights the utility of ascitic IL6 to detect OC importantly at the early stages.

Using a random effect forest plot, we further determined the overall sensitivity and specificity of IL6 in detecting OC from the benign controls. This part of the analysis was conducted in combined stages of OC. The overall sensitivity and specificity levels of both plasma/serum and ascitic IL6 were favorable to discriminate all-stage OC cases from benign controls. This indicates a strong potential for IL6 to be used as a biomarker for OC. However, with this result, the accuracy of IL6 to detect OC specifically at the early stages is still unknown. Two articles showed high sensitivity and specificity provided by serum/plasma IL6 when combined with other markers to detect early-stage OC; however, more studies are needed to confirm these findings [45,77].

In summary, on the basis of our statistical analysis of the combined published data, we found that the levels of circulating and ascitic IL6 are increased with increased stage of OC. The forest plot analyses further showed high accuracy for both plasma/serum and ascitic IL6 to predict OC of mixed stages from the benign controls. For early detection, however, ascitic IL6 from the early-stage OC turned out to be significantly higher than the benign controls, indicating its strong potential as an independent biomarker for early detection of OC. Interestingly, there was no significant correlation between serum/plasma and ascitic IL6, suggesting that IL6 in ascitic fluids may come from other sources and may have distinct functions in the ovarian cancer microenvironment for cancer development. The observation of increased IL6 levels in OC ascites at levels 100 times higher than the serum/plasma levels further suggests IL6 involvement in OC progression within the tumor microenvironment. It has been shown indeed that OC cells secrete IL6 to support its development and metastasis [21]. These observations further suggest that site-specific targeting of the IL6 pathway within the microenvironment may prove to provide additional therapeutic strategies to help control this disease. [87]

Supplementary Materials: The following are available online at https: / www.mdpi.com/article/ 10.3390/jpm11121335/s1, Supplementary Table S1: The details of the selected studies, Supplementary Table S2: STROBE check for the selected studies, Supplementary Table S3: The details of the sensitivity-specificity studies.

Author Contributions: H.A., A.E.R.K. and M.P. conceptualized the study. H.A. and A.E.R.K. conducted the literature research, analyzed the data, and wrote the manuscript. A.E.R.K. designed the whole study and statistics. H.A., A.E.R.K. and M.P. finalized the manuscript. All authors have read and agreed to the published version of the manuscript.

Funding: H.A. was supported by RMIT University PhD scholarship, DR234.

Institutional Review Board Statement: Not applicable.

Informed Consent Statement: Not applicable.

Acknowledgments: Not applicable.

Conflicts of Interest: The authors declare no conflict of interest.

\section{References}

1. Jelovac, D.; Armstrong, D.K. Recent progress in the diagnosis and treatment of ovarian cancer. CA Cancer J. Clin. 2011, 61, 183-203. [CrossRef] [PubMed]

2. Chu, C.S.; Rubin, S.C. Screening for ovarian cancer in the general population. Best Pract. Res. Clin. Obs. Gynaecol. 2006, 20, 307-320. [CrossRef] [PubMed]

3. Lengyel, E. Ovarian cancer development and metastasis. Am. J. Pathol. 2010, 177, 1053-1064. [CrossRef]

4. Parsa, N. Environmental factors inducing human cancers. Iran. J. Public Health 2012, 41, 1-9. [PubMed] 
5. Van Cott, C. Cancer Genetics. Surg. Clin. N. Am. 2020, 100, 483-498. [CrossRef] [PubMed]

6. Dion, L.; Mimoun, C.; Nyangoh Timoh, K.; Bendifallah, S.; Bricou, A.; Collinet, P.; Touboul, C.; Ouldamer, L.; Azaïs, H.; Dabi, Y.; et al. Ovarian Cancer in the Elderly: Time to Move towards a More Logical Approach to Improve Prognosis-A Study from the FRANCOGYN Group. J. Clin. Med. 2020, 9, 1339. [CrossRef]

7. Toss, A.; Tomasello, C.; Razzaboni, E.; Contu, G.; Grandi, G.; Cagnacci, A.; Schilder, R.J.; Cortesi, L. Hereditary ovarian cancer: Not only BRCA 1 and 2 genes. BioMed Res. Int. 2015, 2015, 341723. [CrossRef]

8. Duggan, M.A.; Anderson, W.F.; Altekruse, S.; Penberthy, L.; Sherman, M.E. The Surveillance, Epidemiology, and End Results (SEER) Program and Pathology: Toward Strengthening the Critical Relationship. Am. J. Surg. Pathol. 2016, 40, e94-e102. [CrossRef]

9. Ma, X.; Yu, H. Global burden of cancer. Yale J. Biol. Med. 2006, 79, 85-94. [PubMed]

10. Ataseven, B.; Harter, P.; Grimm, C.; Heitz, F.; Heikaus, S.; Traut, A.; Kahl, A.; Kurzeder, C.; Prader, S.; du Bois, A. The revised 2014 FIGO staging system for epithelial ovarian cancer: Is a subclassification into FIGO stage IVA and IVB justified? Gynecol. Oncol. 2016, 142, 243-247. [CrossRef] [PubMed]

11. Torre, L.A.; Trabert, B.; DeSantis, C.E.; Miller, K.D.; Samimi, G.; Runowicz, C.D.; Gaudet, M.M.; Jemal, A.; Siegel, R.L. Ovarian cancer statistics, 2018. CA Cancer J. Clin. 2018, 68, 284-296. [CrossRef] [PubMed]

12. Rutledge, F.; Barber, H.R.K. Ovarian Carcinoma: Etiology, Diagnosis, and Treatment, 3th ed.; Springer: New York, NY, USA, 1992. [CrossRef]

13. Gumusoglu, E. The Role of Circulating Biomarkers in the Early Diagnosis of Ovarian Cancer; IntechOpen: London, UK, 2018.

14. Meyer, T.; Rustin, G.J.S. Role of tumour markers in monitoring epithelial ovarian cancer. Br. J. Cancer 2000, 82, 1535-1538. [CrossRef]

15. Muyldermans, M.; Cornillie, F.J.; Koninckx, P.R. CA125 and endometriosis. Hum. Reprod. Update 1995, 1, 173-187. [CrossRef] [PubMed]

16. Montagnana, M.; Danese, E.; Giudici, S.; Franchi, M.; Guidi, G.C.; Plebani, M.; Lippi, G. HE4 in Ovarian Cancer; Elsevier Science \& Technology: Amsterdam, The Netherlands, 2011; Volume 55, pp. 1-20.

17. Bristow, R.E.; Santillan, A.; Diaz-Montes, T.P.; Gardner, G.J.; Giuntoli, R.L.; Meisner, B.C.; Frick, K.D.; Armstrong, D.K. Centralization of care for patients with advanced-stage ovarian cancer: A cost-effectiveness analysis. Cancer Interdiscip. Int. J. Am. Cancer Soc. 2007, 109, 1513-1522. [CrossRef] [PubMed]

18. Nassir, M.; Darb-Esfahani, S.; Richter, R.; Chekerov, R.; Hall, C.; Muallem, M.Z.; Denkert, C.; Stamatian, F.; Fotopoulou, C.; Sehouli, J.; et al. HE4 Tissue Expression in Borderline Ovarian Tumors: A Pilot Study by the Tumorbank Ovarian Cancer Network. Anticancer Res. 2013, 33, 1673-1677.

19. Moore, R.G.; Miller, M.C.; Eklund, E.E.; Lu, K.H.; Bast, R.C.; Lambert-Messerlian, G. Serum levels of the ovarian cancer biomarker HE4 are decreased in pregnancy and increase with age. Am. J. Obstet. Gynecol. 2012, 206, 349.e1-349.e7. [CrossRef] [PubMed]

20. Ahmed, A.A.; Abdou, A.M. Diagnostic accuracy of CA125 and HE4 in ovarian carcinoma patients and the effect of confounders on their serum levels. Curr. Probl. Cancer 2019, 43, 450-460. [CrossRef]

21. Browning, L.; Patel, M.R.; Horvath, E.B.; Tawara, K.; Jorcyk, C.L. IL-6 and ovarian cancer: Inflammatory cytokines in promotion of metastasis. Cancer Manag. Res. 2018, 10, 6685-6693. [CrossRef]

22. Quinn, K.M.; Kartikasari, A.E.R.; Cooke, R.E.; Koldej, R.M.; Ritchie, D.S.; Plebanski, M. Impact of age-, cancer-, and treatmentdriven inflammation on T cell function and immunotherapy. J. Leukoc. Biol. 2020, 108, 953-965. [CrossRef] [PubMed]

23. Unver, N.; McAllister, F. IL-6 family cytokines: Key inflammatory mediators as biomarkers and potential therapeutic targets. Cytokine Growth Factor Rev. 2018, 41, 10-17. [CrossRef]

24. Partridge, E.E.; Barnes, M.N. Epithelial ovarian cancer: Prevention, diagnosis, and treatment. CA Cancer J. Clin. 1999, 49, 297-320. [CrossRef] [PubMed]

25. Kampan, N.C.; Madondo, M.T.; Reynolds, J.; Hallo, J.; McNally, O.M.; Jobling, T.W.; Stephens, A.N.; Quinn, M.A.; Plebanski, M. Pre-operative sera interleukin-6 in the diagnosis of high-grade serous ovarian cancer. Sci. Rep. 2020, 10, 2213. [CrossRef] [PubMed]

26. Kishimoto, T. Interleukin-6: Discovery of a pleiotropic cytokine. Arthritis Res Ther. 2006, 8 (Suppl. S2), S2. [CrossRef] [PubMed]

27. Autelitano, D.J.; Raineri, L.; Knight, K.; Bannister, K.; Rice, G.E. Performance of a multianalyte test as an aid for the diagnosis of ovarian cancer in symptomatic women. J. Transl. Med. 2012, 10, 45. [CrossRef] [PubMed]

28. Giuntoli, R.L., 2nd; Webb, T.J.; Zoso, A.; Rogers, O.; Diaz-Montes, T.P.; Bristow, R.E.; Oelke, M. Ovarian cancer-associated ascites demonstrates altered immune environment: Implications for antitumor immunity. Anticancer Res. 2009, 29, $2875-2884$.

29. Kartikasari, A.E.R.; Huertas, C.S.; Mitchell, A.; Plebanski, M. Tumor-Induced Inflammatory Cytokines and the Emerging Diagnostic Devices for Cancer Detection and Prognosis. Front. Oncol. 2021, 11, 692142. [CrossRef]

30. Šimundić, A.M. Measures of Diagnostic Accuracy: Basic Definitions. Ejifcc 2009, 19, $203-211$.

31. Cuschieri, S. The STROBE guidelines. Saudi J. Anaesth. 2019, 13, S31-S34. [CrossRef]

32. Luo, D.H.; Wan, X.; Liu, J.M.; Tong, T.J. Optimally estimating the sample mean from the sample size, median, mid-range, and/or mid-quartile range. Stat. Methods Med. Res. 2018, 27, 1785-1805. [CrossRef]

33. Baratloo, A.; Hosseini, M.; Negida, A.; El Ashal, G. Part 1: Simple Definition and Calculation of Accuracy, Sensitivity and Specificity. Emergency 2015, 3, 48-49. [PubMed] 
34. Wallace, B.C.; Schmid, C.H.; Lau, J.; Trikalinos, T.A. Meta-Analyst: Software for meta-analysis of binary, continuous and diagnostic data. BMC Med. Res. Methodol. 2009, 9, 80. [CrossRef]

35. Sanna, E.; Tanca, L.; Cherchi, C.; Gramignano, G.; Oppi, S.; Chiai, M.G.; Macciò, A.; Madeddu, C. Decrease in Neutrophil-toLymphocyte Ratio during Neoadjuvant Chemotherapy as a Predictive and Prognostic Marker in Advanced Ovarian Cancer. Diagnostics 2021, 11, 1298. [CrossRef] [PubMed]

36. Micheli, D.C.; Jammal, M.P.; Martins-Filho, A.; Côrtes, J.R.X.D.M.; Souza, C.N.D.; Nomelini, R.S.; Murta, E.F.C.; Tavares-Murta, B.M. Serum cytokines and CXCR2: Potential tumour markers in ovarian neoplasms. Biomarkers 2020, 25, 474-482. [CrossRef]

37. de Lima, C.A.; Silva Rodrigues, I.S.; Martins-Filho, A.; Côbo Micheli, D.; Martins Tavares-Murta, B.; Candido Murta, E.F.; Simões Nomelini, R. Cytokines in peritoneal fluid of ovarian neoplasms. J. Obstet. Gynaecol. 2020, 40, 401-405. [CrossRef] [PubMed]

38. Rodrigues, I.S.S.; Martins-Filho, A.; Micheli, D.C.; Lima, C.A.; Tavares-Murta, B.M.; Murta, E.F.C.; Nomelini, R.S. IL-6 and IL-8 as Prognostic Factors in Peritoneal Fluid of Ovarian Cancer. Immunol. Investig. 2020, 49, 510-521. [CrossRef] [PubMed]

39. Wertel, I.; Suszczyk, D.; Pawłowska, A.; Bilska, M.; Chudzik, A.; Skiba, W.; Paduch, R.; Kotarski, J. Prognostic and Clinical Value of Interleukin 6 and CD45(+)CD14(+) Inflammatory Cells with PD-L1(+)/PD-L2(+) Expression in Patients with Different Manifestation of Ovarian Cancer. J. Immunol. Res. 2020, 2020, 1715064. [CrossRef] [PubMed]

40. Zhang, H.; Chen, C.; Wang, S.; Li, X.; Fan, T. Efficacy of bevacizumab combined with nedaplatin in the treatment of ovarian cancer and its effects on tumor markers and immunity of patients. J. BUON 2020, 25, 80-86.

41. Crispim, P.C.A.; Jammal, M.P.; Antão, P.K.A.; Micheli, D.C.; Tavares-Murta, B.M.; Murta, E.F.C.; Nomelini, R.S. IL6, IL8, and IL10 in the distinction of malignant ovarian neoplasms and endometriomas. Am. J. Reprod. Immunol. 2020, 84, e13309. [CrossRef]

42. Shi, J.; Huo, R.; Li, N.; Li, H.; Zhai, T.; Li, H.; Shen, B.; Ye, J.; Fu, R.; Di, W. CYR61, a potential biomarker of tumor inflammatory response in epithelial ovarian cancer microenvironment of tumor progress. BMC Cancer 2019, 19, 1-9. [CrossRef]

43. Li, G.; Zhang, K.; Gong, F.; Jin, H. A study on changes and clinical significance of blood glucose, blood lipid and inflammation in patients with ovarian cancer. J. BUON 2019, 24, 2322-2326.

44. Dalal, V.; Kumar, R.; Kumar, S.; Sharma, A.; Kumar, L.; Sharma, J.B.; Roy, K.K.; Singh, N.; Vanamail, P. Biomarker potential of IL-6 and VEGF-A in ascitic fluid of epithelial ovarian cancer patients. Clin. Chim. Acta 2018, 482, 27-32. [CrossRef] [PubMed]

45. Han, C.; Bellone, S.; Siegel, E.R.; Altwerger, G.; Menderes, G.; Bonazzoli, E.; Egawa-Takata, T.; Pettinella, F.; Bianchi, A.; Riccio, F.; et al. A novel multiple biomarker panel for the early detection of high-grade serous ovarian carcinoma. Gynecol. Oncol. 2018, 149, 585-591. [CrossRef] [PubMed]

46. Inflammatory and Nutritional Serum Markers as Predictors of Peri-operative Morbidity and Survival in Ovarian Cancer. Anticancer Res. 2017, 37. [CrossRef]

47. Martins-Filho, A.; Jammal, M.P.; Micheli, D.C.; Tavares-Murta, B.M.; Etchebehere, R.M.; Murta, E.F.C.; Nomelini, R.S. Role of Intracystic Cytokines and Nitric Oxide in Ovarian Neoplasms. Scand. J. Immunol. 2017, 86, 462-470. [CrossRef] [PubMed]

48. Cantón-Romero, J.C.; Miranda-Díaz, A.G.; Bañuelos-Ramírez, J.L.; Carrillo-Ibarra, S.; Sifuentes-Franco, S.; Castellanos-González, J.A.; Rodríguez-Carrizalez, A.D. Markers of Oxidative Stress and Inflammation in Ascites and Plasma in Patients with PlatinumSensitive, Platinum-Resistant, and Platinum-Refractory Epithelial Ovarian Cancer. Oxidative Med. Cell. Longev. 2017, 2017, 2873030. [CrossRef]

49. Sanguinete, M.M.M.; Oliveira, P.H.; Martins-Filho, A.; Micheli, D.C.; Tavares-Murta, B.M.; Murta, E.F.C.; Nomelini, R.S. Serum IL-6 and IL-8 Correlate with Prognostic Factors in Ovarian Cancer. Immunol. Investig. 2017, 46, 677-688. [CrossRef] [PubMed]

50. Hao, C.J.; Li, J.; Liu, P.; Li, X.L.; Hu, Y.Q.; Sun, J.C.; Wei, Y. Effects of the balance between type 1 and type 2 T helper cells on ovarian cancer. Genet. Mol. Res. 2016, 15. [CrossRef]

51. Mikuła-Pietrasik, J.; Uruski, P.; Szubert, S.; Moszyński, R.; Szpurek, D.; Sajdak, S.; Tykarski, A.; Książek, K. Biochemical composition of malignant ascites determines high aggressiveness of undifferentiated ovarian tumors. Med. Oncol. 2016, 33, 94. [CrossRef]

52. Chudecka-Głaz, A.M.; Cymbaluk-Płoska, A.A.; Menkiszak, J.L.; Pius-Sadowska, E.; Machaliński, B.B.; Sompolska-Rzechuła, A.; Rzepka-Górska, I.A. Assessment of selected cytokines, proteins, and growth factors in the peritoneal fluid of patients with ovarian cancer and benign gynecological conditions. Onco Targets Ther. 2015, 8, 471-485. [CrossRef]

53. Block, M.S.; Maurer, M.J.; Goergen, K.; Kalli, K.R.; Erskine, C.L.; Behrens, M.D.; Oberg, A.L.; Knutson, K.L. Plasma immune analytes in patients with epithelial ovarian cancer. Cytokine 2015, 73, 108-113. [CrossRef]

54. Matsuo, K.; Hasegawa, K.; Yoshino, K.; Murakami, R.; Hisamatsu, T.; Stone, R.L.; Previs, R.A.; Hansen, J.M.; Ikeda, Y.; Miyara, A.; et al. Venous thromboembolism, interleukin-6 and survival outcomes in patients with advanced ovarian clear cell carcinoma. Eur. J. Cancer 2015, 51, 1978-1988. [CrossRef]

55. Ose, J.; Schock, H.; Tjønneland, A.; Hansen, L.; Overvad, K.; Dossus, L.; Clavel-Chapelon, F.; Baglietto, L.; Boeing, H.; Trichopolou, A.; et al. Inflammatory Markers and Risk of Epithelial Ovarian Cancer by Tumor Subtypes: The EPIC Cohort. Cancer Epidemiol. Biomark. Prev. 2015, 24, 951-961. [CrossRef] [PubMed]

56. Lane, D.; Matte, I.; Garde-Granger, P.; Laplante, C.; Carignan, A.; Rancourt, C.; Piché, A. Inflammation-regulating factors in ascites as predictive biomarkers of drug resistance and progression-free survival in serous epithelial ovarian cancers. BMC Cancer 2015, 15, 492. [CrossRef] [PubMed]

57. Trabert, B.; Pinto, L.; Hartge, P.; Kemp, T.; Black, A.; Sherman, M.E.; Brinton, L.A.; Pfeiffer, R.M.; Shiels, M.S.; Chaturvedi, A.K.; et al. Pre-diagnostic serum levels of inflammation markers and risk of ovarian cancer in the prostate, lung, colorectal and ovarian cancer (PLCO) screening trial. Gynecol. Oncol. 2014, 135, 297-304. [CrossRef] [PubMed] 
58. Cândido, E.B.; Silva, L.M.; Carvalho, A.T.; Lamaita, R.M.; Filho, R.M.; Cota, B.D.; da Silva-Filho, A.L. Immune response evaluation through determination of type 1, type 2, and type 17 patterns in patients with epithelial ovarian cancer. Reprod. Sci. 2013, 20, 828-837. [CrossRef] [PubMed]

59. Poole, E.M.; Lee, I.M.; Ridker, P.M.; Buring, J.E.; Hankinson, S.E.; Tworoger, S.S. A prospective study of circulating C-reactive protein, interleukin-6, and tumor necrosis factor $\alpha$ receptor 2 levels and risk of ovarian cancer. Am. J. Epidemiol. 2013, 178, 1256-1264. [CrossRef]

60. Dobrzycka, B.; Mackowiak-Matejczyk, B.; Terlikowska, K.M.; Kulesza-Bronczyk, B.; Kinalski, M.; Terlikowski, S.J. Serum levels of IL-6, IL-8 and CRP as prognostic factors in epithelial ovarian cancer. Eur. Cytokine Netw. 2013, 24, 106-113. [CrossRef] [PubMed]

61. Matte, I.; Lane, D.; Laplante, C.; Rancourt, C.; Piché, A. Profiling of cytokines in human epithelial ovarian cancer ascites. Am. J. Cancer Res. 2012, 2, 566-580.

62. Clendenen, T.V.; Lundin, E.; Zeleniuch-Jacquotte, A.; Koenig, K.L.; Berrino, F.; Lukanova, A.; Lokshin, A.E.; Idahl, A.; Ohlson, N.; Hallmans, G.; et al. Circulating Inflammation Markers and Risk of Epithelial Ovarian Cancer. Cancer Epidemiol. Biomark. Prev. 2011, 20, 799-810. [CrossRef]

63. Sen, S.; Kuru, O.; Akbayir, O.; Oguz, H.; Yasasever, V.; Berkman, S. Determination of serum CRP, VEGF, Leptin, CK-MB, CA-15-3 and IL-6 levels for malignancy prediction in adnexal masses. J. Turk. Ger. Gynecol. Assoc. 2011, 12, 214-219. [CrossRef]

64. Yigit, R.; Figdor, C.G.; Zusterzeel, P.L.; Pots, J.M.; Torensma, R.; Massuger, L.F. Cytokine analysis as a tool to understand tumour-host interaction in ovarian cancer. Eur. J. Cancer 2011, 47, 1883-1889. [CrossRef]

65. Edgell, T.; Martin-Roussety, G.; Barker, G.; Autelitano, D.J.; Allen, D.; Grant, P.; Rice, G.E. Phase II biomarker trial of a multimarker diagnostic for ovarian cancer. J. Cancer Res. Clin. Oncol. 2010, 136, 1079-1088. [CrossRef] [PubMed]

66. Nowak, M.; Glowacka, E.; Szpakowski, M.; Szyllo, K.; Malinowski, A.; Kulig, A.; Tchorzewski, H.; Wilczynski, J. Proinflammatory and immunosuppressive serum, ascites and cyst fluid cytokines in patients with early and advanced ovarian cancer and benign ovarian tumors. Neuro Endocrinol. Lett. 2010, 31, 375-383. [PubMed]

67. Napoletano, C.; Bellati, F.; Landi, R.; Pauselli, S.; Marchetti, C.; Visconti, V.; Sale, P.; Liberati, M.; Rughetti, A.; Frati, L.; et al. Ovarian cancer cytoreduction induces changes in T cell population subsets reducing immunosuppression. J. Cell. Mol. Med. 2010, 14, 2748-2759. [CrossRef]

68. Tsai-Turton, M.; Santillan, A.; Lu, D.; Bristow, R.E.; Chan, K.C.; Shih Ie, M.; Roden, R.B. p53 autoantibodies, cytokine levels and ovarian carcinogenesis. Gynecol. Oncol. 2009, 114, 12-17. [CrossRef] [PubMed]

69. Amonkar, S.D.; Bertenshaw, G.P.; Chen, T.-H.; Bergstrom, K.J.; Zhao, J.; Seshaiah, P.; Yip, P.; Mansfield, B.C. Development and Preliminary Evaluation of a Multivariate Index Assay for Ovarian Cancer. PLoS ONE 2009, 4, e4599. [CrossRef]

70. Macciò, A.; Madeddu, C.; Massa, D.; Astara, G.; Farci, D.; Melis, G.B.; Mantovani, G. Interleukin-6 and leptin as markers of energy metabolicchanges in advanced ovarian cancer patients. J. Cell. Mol. Med. 2009, 13, 3951-3959. [CrossRef] [PubMed]

71. Lutgendorf, S.K.; Weinrib, A.Z.; Penedo, F.; Russell, D.; DeGeest, K.; Costanzo, E.S.; Henderson, P.J.; Sephton, S.E.; Rohleder, N.; Lucci, J.A., 3rd; et al. Interleukin-6, cortisol, and depressive symptoms in ovarian cancer patients. J. Clin. Oncol. 2008, 26, 4820-4827. [CrossRef]

72. Kavsak, P.A.; Lee, A.; Hirte, H.; Young, E.; Gauldie, J. Cytokine elevations in acute coronary syndrome and ovarian cancer: A mechanism for the up-regulation of the acute phase proteins in these different disease etiologies. Clin. Biochem. 2008, 41, 607-610. [CrossRef]

73. Lambeck, A.J.A.; Crijns, A.P.G.; Leffers, N.; Sluiter, W.J.; Ten Hoor, K.A.; Braid, M.; Van Der Zee, A.G.J.; Daemen, T.; Nijman, H.W.; Kast, W.M. Serum Cytokine Profiling as a Diagnostic and Prognostic Tool in Ovarian Cancer: A Potential Role for Interleukin 7. Clin. Cancer Res. 2007, 13, 2385-2391. [CrossRef]

74. Chechlinska, M.; Kaminska, J.; Markowska, J.; Kramar, A.; Steffen, J. Peritoneal fluid cytokines and the differential diagnosis of benign and malignant ovarian tumors and residual/recurrent disease examination. Int. J. Biol. Markers 2007, 22, 172-180. [CrossRef] [PubMed]

75. Costanzo, E.S.; Lutgendorf, S.K.; Sood, A.K.; Anderson, B.; Sorosky, J.; Lubaroff, D.M. Psychosocial factors and interleukin-6 among women with advanced ovarian cancer. Cancer 2005, 104, 305-313. [CrossRef] [PubMed]

76. Macciò, A.; Madeddu, C.; Massa, D.; Mudu, M.C.; Lusso, M.R.; Gramignano, G.; Serpe, R.; Melis, G.B.; Mantovani, G. Hemoglobin levels correlate with interleukin-6 levels in patients with advanced untreated epithelial ovarian cancer: Role of inflammation in cancer-related anemia. Blood 2005, 106, 362-367. [CrossRef]

77. Gorelik, E. Multiplexed Immunobead-Based Cytokine Profiling for Early Detection of Ovarian Cancer. Cancer Epidemiol. Biomark. Prev. 2005, 14, 981-987. [CrossRef] [PubMed]

78. Daraï, E.; Detchev, R.; Hugol, D.; Quang, N.T. Serum and cyst fluid levels of interleukin (IL) -6, IL-8 and tumour necrosis factor-alpha in women with endometriomas and benign and malignant cystic ovarian tumours. Hum. Reprod. 2003, 18, 1681-1685. [CrossRef] [PubMed]

79. Dobryszycka, W.; Katnik-Prastowska, I.; Gerber, J.; Lemańska, K.; Utko, K.; Rozdolski, K. Serum haptoglobin, CA 125 and interleukin 6 levels in malignant and non-malignant tumors of the ovary. Arch. Immunol. Ther. Exp. Warsz 1999, 47, $229-236$.

80. Tempfer, C.; Zeisler, H.; Sliutz, G.; Haeusler, G.; Hanzal, E.; Kainz, C. Serum Evaluation of Interleukin 6 in Ovarian Cancer Patients. Gynecol. Oncol. 1997, 66, 27-30. [CrossRef] 
81. Scambia, G.; Testa, U.; Benedetti Panici, P.; Foti, E.; Martucci, R.; Gadducci, A.; Perillo, A.; Facchini, V.; Peschle, C.; Mancuso, S. Prognostic significance of interleukin 6 serum levels in patients with ovarian cancer. Br. J. Cancer 1995, 71, 354-356. [CrossRef] [PubMed]

82. Plante, M.; Rubin, S.C.; Wong, G.Y.; Federici, M.G.; Finstad, C.L.; Gastl, G.A. Interleukin-6 level in serum and ascites as a prognostic factor in patients with epithelial ovarian cancer. Cancer 1994, 73, 1882-1888. [CrossRef]

83. Schröder, W.; Ruppert, C.; Bender, H.G. Concomitant measurements of interleukin-6 (IL-6) in serum and peritoneal fluid of patients with benign and malignant ovarian tumors. Eur. J. Obstet. Gynecol. Reprod. Biol. 1994, 56, 43-46. [CrossRef]

84. van der Zee, A.G.; de Cuyper, E.M.; Limburg, P.C.; de Bruijn, H.W.; Hollema, H.; Bijzet, J.; Krans, M.; de Vries, E.G. Higher levels of interleukin-6 in cystic fluids from patients with malignant versus benign ovarian tumors correlate with decreased hemoglobin levels and increased platelet counts. Cancer 1995, 75, 1004-1009. [CrossRef]

85. Moradi, M.M.; Carson, L.F.; Weinberg, B.; Haney, A.F.; Twiggs, L.B.; Ramakrishnan, S. Serum and ascitic fluid levels of interleukin1, interleukin-6, and tumor necrosis factor-alpha in patients with ovarian epithelial cancer. Cancer 1993, 72, 2433-2440. [CrossRef]

86. Gastl, G.; Plante, M.; Finstad, C.L.; Wong, G.Y.; Federici, M.G.; Bander, N.H.; Rubin, S.C. High IL-6 levels in ascitic fluid correlate with reactive thrombocytosis in patients with epithelial ovarian cancer. Br. J. Haematol. 1993, 83, 433-441. [CrossRef] [PubMed]

87. Berek, J.S.; Chung, C.; Kaldi, K.; Watson, J.M.; Knox, R.M.; Martínez-Maza, O. Serum interleukin-6 levels correlate with disease status in patients with epithelial ovarian cancer. Am. J. Obstet. Gynecol. 1991, 164, 1038-1042. [CrossRef] 